\title{
Valor nutricional de forragem de pastagens manejadas durante o período hibernal
}

\author{
Nutritive value of forage of pastures managed during cool-season
}

\author{
Clair Jorge OlivoI Gilmar Roberto Meinerz ${ }^{\text {II }}$ José Laerte Nörnberg ${ }^{\text {IV }}$ Carlos Alberto Agnolin ${ }^{\text {III }}$ \\ Edilene Steinwandter ${ }^{\mathrm{III}}$ Vanessa Peripolli ${ }^{\mathrm{II}}$ Franciele Hohenreuther ${ }^{\mathrm{II}}$ Suziane Ghedini Martinelli ${ }^{\mathrm{II}}$ \\ Dirlaine Ilha Martins ${ }^{\text {II }}$
}

\section{RESUMO}

O objetivo nesta pesquisa foi avaliar o valor nutritivo, determinando-se a matéria orgânica (MO), digestibilidade in vitro da MO (DIVMO), nutrientes digestíveis totais (NDT), digestibilidade in vitro da matéria seca (DIVMS), proteína bruta $(P B)$ e fibra em detergente neutro (FDN), de quatro sistemas forrageiros (tratamentos), pastejados por vacas da raça Holandesa. Os tratamentos foram constituídos por "coastcross" (Cynodon dactylon L. Pers.) sobresemeada com azevém (Lolium multiflorium Lam. cv. 'Comum'); coastcross sobresemeada com azevém e trevo branco (Trifolium repens L., cv. 'Yi'); azevém mais trevo branco e apenas azevém. Entre 15 de maio e 24 de outubro de 2006, foram conduzidos cinco ciclos de pastejo, sendo avaliada a massa de forragem de prépastejo (MF), as composições botânica e estrutural e lotação (L). Para análise do valor nutritivo, foram coletadas amostras de pastejo simulado. O delineamento experimental foi inteiramente casualizado com quatro tratamentos e duas repetições (piquetes). Não foram detectadas diferenças entre os tratamentos para as médias de MF e L. Observou-se que os melhores resultados de valor nutritivo estão associados à biomassa de lâmina foliar de azevém em todas as pastagens. Verificaram-se pequenas diferenças no valor nutritivo entre as pastagens sobresemeadas em comparação ao azevém e trevo branco ou azevém. Os valores médios de MO, DIVMO, NDT, DIVMS, PB e FDN das pastagens foram de 89,52; 69,50; 60,$95 ; 70,96 ; 23,03$ e 51,87\%, respectivamente.

Palavras-chave: azevém, coastcross, composição botânica, trevo branco, valor nutritivo.

\section{ABSTRACT}

This research aimed at evaluating the nutritive value by determining the organic matter (OM), in vitro $O M$ digestibility (IVOMD), total digestibility nutrient (TDN), in vitro dry matter digestibility (IVDMD), crude protein (CP) and neutral detergent fiber (NDF) of four pasture-based system grazed by Holstein cows. The treatments were sod seeding of ryegrass (Lolium multiflorium Lam. cv. 'Common') over coastcross (Cynodon dactylon L. Pers.,); sod seeding of ryegrass plus white clover (Trifolium repens L., cv. 'Yi') over coastcross ryegrass plus white clover or ryegrass. From May $15^{\text {th }}$ to October $24^{\text {th }}$, 2006, in five grazing periods, the pregraze herbage mass $(P M)$, botanical and structural compositions and stocking rate (SR) were evaluated. Hand-plucked samples were collected to analyze the nutritive value. The experimental design was completely randomized, with four treatments (pastures) and two replications (paddocks). Differences in PM and SR averages were not detected among treatments. Better results of nutritive value were associated of ryegrass leaf lamina biomass in all pastures. Small differences on nutritive value were observed on sod seeding 'coastcross' systems compared to ryegrass plus white clover or ryegrass pastures. The mean values of OM, IVOMD, TDN, IVDMD, CP and NDF of the pastures were 89.52; $69.50 ; 60.95 ; 70.96 ; 23.03$ and $51.87 \%$, respectively.

Key words: botanical composition, 'coastcross', nutritive value, ryegrass, white clover.

\section{INTRODUÇÃO}

A utilização de pastagem do gênero Cynodon tem crescido notadamente em propriedades leiteiras da Mesorregião Noroeste do Rio Grande do Sul. Como vantagens dessas gramíneas, destacam-se o elevado potencial produtivo, resposta à fertilidade

'Departamento de Zootecnia (DZ), Universidade Federal de Santa Maria (UFSM), 97105-900, Santa Maria, RS, Brasil. E-mail: clairo@ccr.usfm.br. Autor para correspondência.

"Curso de Zootecnia, UFSM, Santa Maria, RS, Brasil.

IIIPrograma de Pós-graduação em Zootecnia, UFSM, Santa Maria, RS, Brasil.

${ }^{\mathrm{IV}}$ Departamento de Tecnologia e Ciência dos Alimentos, UFSM, Santa Maria, RS, Brasil. 
do solo, adaptação a diferentes ambientes e flexibilidade de uso como pastagem, feno e silagem (CARNEVALLI et al., 2001). Estudos conduzidos em três anos consecutivos por VILELA et al. (2006) com coastcross, submetido ao pastejo rotacionado com vacas em lactação, recebendo diariamente diferentes quantidades de concentrado, 3 e $6 \mathrm{~kg}$, demonstraram produções médias individuais de 15,5 e 19,1kg de leite, respectivamente, com lotação próxima a 5 vacas dia ${ }^{-1} \mathrm{ha}^{-1}$.

Outras características dessas gramíneas, como a perenidade e o hábito rasteiro, contribuem para manutenção da cobertura do solo (CARNEVALLI et al., 2001). Esse comportamento aliado ao fato de serem sensíveis ao frio favorece a consorciação com espécies forrageiras de inverno, introduzidas mediante sobresemeadura. Esses sistemas forrageiros vêm sendo usados pelos produtores, havendo, no entanto, escassez de informações sobre a qualidade de forragem dessas pastagens.

O objetivo, no presente trabalho, foi avaliar a qualidade de forragem de pastagens constituídas por azevém com e sem trevo branco e da sobresemeadura dessas forrageiras em coastcross.

\section{MATERIAL E MÉTODOS}

O experimento foi conduzido no Laboratório de Bovinocultura de Leite do Departamento de Zootecnia e as análises laboratoriais foram feitas no Núcleo Integrado de Desenvolvimento em Análises Laboratoriais (NIDAL), da Universidade Federal de Santa Maria (UFSM), localizada na região fisiográfica denominada Depressão Central do Rio Grande do Sul, com altitude de $95 \mathrm{~m}$, latitude de $29^{\circ} 43^{\prime}$ ' sul e longitude de $53^{\circ} 42^{\prime}$ oeste. O solo da área experimental é classificado como Argissolo Vermelho Distrófico Arênico, pertencente à unidade de mapeamento São Pedro (EMBRAPA, 1999). O clima da região é o Cfa (subtropical úmido), conforme classificação de Köppen (MORENO, 1961).

O período experimental foi compreendido entre maio e outubro de 2006, totalizando 161 dias. As médias mensais de temperatura e precipitação foram de $16,1^{\circ} \mathrm{C}$ e $117,4 \mathrm{~mm}$, respectivamente. Os dados foram coletados na Estação Experimental Meteorológica da UFSM, situada em torno de 500 metros da área experimental.

A área utilizada foi de 1,40ha, parte (0,18ha), usada para o cultivo de azevém, para adaptação dos animais e o restante (1,22ha), subdividida em oito piquetes, destinados ao estabelecimento das pastagens experimentais. Os tratamentos foram constituídos por pastagens de azevém + coastcross
$(\mathrm{AZ}+\mathrm{CC})$, azevém + coastcross + trevo branco $(\mathrm{AZ}+\mathrm{CC}+\mathrm{TB})$, azevém + trevo branco $(\mathrm{AZ}+\mathrm{TB})$ e o azevém (AZ).

Em metade da área, a coastcross já havia sido implantada em março de 2003, manualmente, através de mudas provenientes da subdivisão de touceiras. Em meados de maio de 2006, foi realizada a roçada da área e, posteriormente, uma gradagem leve. Na seqüência, fez-se a distribuição a lanço do azevém $(\mathrm{AZ}+\mathrm{CC})$ ou da mistura constituída por azevém mais trevo branco (AZ+CC+TB). A seguir, passou-se uma gradagem leve para cobrir as sementes. No restante da área, fez-se o estabelecimento das pastagens em cultivo estreme (AZ+ TB e AZ), preparando-se o solo com duas gradagens. Para distribuição e cobertura das sementes usou-se o mesmo procedimento dos tratamentos $\mathrm{AZ}+\mathrm{CC}$ e $\mathrm{AZ}+\mathrm{CC}+\mathrm{TB}$. A densidade de semeadura do azevém foi de $35 \mathrm{~kg} \mathrm{ha}^{-1}$ e a do trevo branco foi de $3 \mathrm{~kg} \mathrm{ha}^{-1}$.

Para adubação de base, utilizaram-se 10; 40 e $60 \mathrm{~kg} \mathrm{ha}^{-1}$ de $\mathrm{N}$; P e K, respectivamente, baseando-se na análise do solo (COMISSÃO DE QUÍMICA E FERTILIDADE DO SOLO-RS/SC, 2004). A adubação de cobertura consistiu de quatro aplicações de uréia, sendo a primeira 30 dias após a semeadura e as demais nos dias 17/07, 14/08 e 10/10, perfazendo um total de 140kg de $\mathrm{N} \mathrm{ha}^{-1}$.

A massa de forragem foi determinada através da técnica de dupla amostragem (WILM et al., 1944). A forragem proveniente das amostras cortadas foi homogeneizada, sendo retirada uma subamostra para estimativa das composições botânica da pastagem e estrutural do azevém e da coastcross. As amostras foram secas em estufa de ar forçado, com temperatura entre $55^{\circ}$ e $60^{\circ} \mathrm{C}$, por 72 horas, para estimativa da produção de matéria seca (MS).

O sistema de pastejo adotado foi o rotacionado, com um dia de ocupação, tendo como critério para entrada dos animais a disponibilidade de massa de forragem entre 1.600 e $2.000 \mathrm{~kg}_{\text {de }} \mathrm{MS} \mathrm{ha}^{-1}$. A carga animal foi calculada, buscando manter-se um resíduo de forragem de $900 \mathrm{~kg}_{\text {de }} \mathrm{MS} \mathrm{ha}^{-1}$, adotando-se um valor estimado de taxa desaparecimento de MS de 3\% do peso vivo.

Como animais experimentais foram utilizadas vacas em lactação da raça holandesa submetidas a duas ordenhas diárias, às $7 \mathrm{~h}$ e às $16 \mathrm{~h}$, permanecendo nas pastagens das $9 \mathrm{~h}$ às $15 \mathrm{~h} 30 \mathrm{~min}$ e das $18 \mathrm{~h}$ às $6 \mathrm{~h} 30 \mathrm{~min}$. Como complementação alimentar, cada animal recebeu, diariamente, $4 \mathrm{~kg}$ de concentrado, com $20 \%$ de PB e $1,0 \mathrm{~kg}$ de MS de silagem de sorgo. Os animais foram pesados, quinzenalmente, sempre após a ordenha da tarde. 
Para a determinação do valor nutritivo da forragem, foram coletadas amostras pela simulação de pastejo (EUCLIDES et al., 1992), após a observação do comportamento ingestivo das vacas por 15 minutos, no início e no final do pastejo. As amostras foram pesadas, parcialmente secas em estufa com ar forçado, moídas em moinho do tipo "Willey” e, posteriormente, analisadas em laboratório quanto a $\mathrm{PB}$, pelo método de Kjeldahl (AOAC, 1995), MS em estufa a $105^{\circ} \mathrm{C}$, FDN (VAN SOEST et al., 1991), DIVMS e DIVMO (TILLEY \& TERRY, 1963). Para estimar o NDT das pastagens, foi utilizada a equação: NDT $=$ MO $\{[26,8+0,595$ (DIVMO)]/100\}, descrita por KUNKLE \& BATES (1998), na qual NDT refere-se aos nutrientes digestíveis totais (\%); MO é a matéria orgânica (\%) e DIVMO é a digestibilidade in vitro da matéria orgânica (\%).

O delineamento experimental utilizado foi o inteiramente casualizado, com quatro tratamentos, duas repetições (piquetes) e cinco períodos de avaliação (pastejos). Os dados foram submetidos à análise de variância e as médias comparadas pelo teste de Tukey, em nível de 5\% de significância. Também foram realizadas análises de regressão polinomial, em função dos dias de pastejo, e de correlação, pelo coeficiente de Pearson, entre as variáveis climáticas, de valor nutritivo, da massa de forragem e das composições botânica e estrutural. As análises foram efetuadas com auxílio do pacote estatístico SAS (1997).

\section{RESULTADOS E DISCUSSÃO}

Os dados referentes à massa de forragem, à composição botânica e estrutural das pastagens encontram-se na tabela 1 . Foram conduzidos cinco ciclos de pastejo com tempos médios de ocupação de um dia e de descanso de 31 dias. Esses resultados são

Tabela 1 - Massa de forragem de pré-pastejo ( $\mathrm{kg}$ de matéria seca ha ${ }^{-1}$ ), composições (\%) botânica e estrutural nas pastagens constituídas por azevém + "coastcross" (AZ+CC), azevém + "coastcross" + trevo branco (AZ+CC+TB), azevém + trevo branco(AZ+ TB) e o azevém (AZ). Santa Maria, RS, 2006.

\begin{tabular}{|c|c|c|c|c|c|c|c|c|}
\hline \multirow{2}{*}{ Parâmetros } & \multirow{2}{*}{ Pastagem } & \multicolumn{5}{|c|}{---------------------------------------Pastejos------------------------------------ } & \multirow[b]{2}{*}{ Média } & \multirow{2}{*}{ CV (\%) } \\
\hline & & $1^{\mathrm{o}}(\mathrm{jun} / 06)$ & $2^{\circ}(\mathrm{jul} / 06)$ & $3^{\circ}($ ago/06) & $4^{\circ}($ set $/ 06)$ & $5^{\circ}($ out $/ 06)$ & & \\
\hline \multirow{4}{*}{$\begin{array}{l}\text { Massa de } \\
\text { forragem }\end{array}$} & $\mathrm{AZ}+\mathrm{CC}$ & 2128 & 2336 & 2122 & $3180^{\mathrm{ab}}$ & 2579 & 2469 & \multirow{4}{*}{13,39} \\
\hline & $\mathrm{AZ}+\mathrm{CC}+\mathrm{TB}$ & 1754 & 2221 & 2126 & $3844^{\mathrm{a}}$ & 2126 & 2414 & \\
\hline & $\mathrm{AZ}+\mathrm{TB}$ & 1587 & 1802 & 2508 & $2888^{b}$ & 1989 & 2155 & \\
\hline & $\mathrm{AZ}$ & 1715 & 1902 & 2550 & $2610^{\mathrm{b}}$ & 1978 & 2151 & \\
\hline \multirow{4}{*}{ Folha azevém } & $\mathrm{AZ}+\mathrm{CC}$ & $48,01^{\mathrm{b}}$ & $41,77^{\mathrm{c}}$ & 36,79 & $28,11^{\mathrm{ab}}$ & 14,56 & $32,45^{\mathrm{b}}$ & \multirow{4}{*}{13,27} \\
\hline & $\mathrm{AZ}+\mathrm{CC}+\mathrm{TB}$ & $32,67^{b}$ & $44,46^{\mathrm{bc}}$ & 41,61 & $25,52^{b}$ & 13,70 & $31,59^{\mathrm{b}}$ & \\
\hline & $\mathrm{AZ}+\mathrm{TB}$ & $78,68^{\mathrm{a}}$ & $65,23^{\mathrm{ab}}$ & 12,96 & $40,98^{\mathrm{a}}$ & 12,82 & $42,13^{a}$ & \\
\hline & $\mathrm{AZ}$ & $73,53^{\mathrm{a}}$ & $73,07^{\mathrm{a}}$ & 12,51 & $37,09^{\mathrm{ab}}$ & 12,51 & $42,34^{\mathrm{a}}$ & \\
\hline \multirow{4}{*}{ Colmo azevém } & $\mathrm{AZ}+\mathrm{CC}$ & $9,37^{\mathrm{bc}}$ & 13,85 & 24,41 & $49,94^{\mathrm{b}}$ & $49,42^{\mathrm{b}}$ & $29,40^{\mathrm{b}}$ & \multirow{4}{*}{16,26} \\
\hline & $\mathrm{AZ}+\mathrm{CC}+\mathrm{TB}$ & $6,98^{\mathrm{c}}$ & 12,39 & 14,14 & $55,40^{\mathrm{b}}$ & $41,11^{\mathrm{b}}$ & $26,00^{\mathrm{b}}$ & \\
\hline & $\mathrm{AZ}+\mathrm{TB}$ & $14,05^{\mathrm{ab}}$ & 19,02 & 75,04 & $43,93^{\mathrm{a}}$ & $74,42^{\mathrm{a}}$ & $45,29^{\mathrm{a}}$ & \\
\hline & $\mathrm{AZ}$ & $18,86^{\mathrm{a}}$ & 19,24 & 62,99 & $55,17^{\mathrm{a}}$ & $62,99^{a}$ & $43,85^{\mathrm{a}}$ & \\
\hline \multirow{4}{*}{ Material morto } & $\mathrm{AZ}+\mathrm{CC}$ & $13,78^{a}$ & 13,51 & 19,78 & 11,32 & 20,71 & 15,82 & \multirow{4}{*}{53,51} \\
\hline & $\mathrm{AZ}+\mathrm{CC}+\mathrm{TB}$ & $14,42^{\mathrm{a}}$ & 16,98 & 17,35 & 5,60 & 17,22 & 14,31 & \\
\hline & $\mathrm{AZ}+\mathrm{TB}$ & $1,55^{\mathrm{b}}$ & 11,51 & 10,36 & 10,08 & 10,24 & 8,75 & \\
\hline & $\mathrm{AZ}$ & $1,58^{\mathrm{b}}$ & 6,70 & 20,35 & 4,55 & 20,35 & 10,70 & \\
\hline Folha & $\mathrm{AZ}+\mathrm{CC}$ & 17,77 & 13,43 & 6,48 & 3,86 & 7,11 & 10,13 & \multirow{2}{*}{32,04} \\
\hline Coastcross & $\mathrm{AZ}+\mathrm{CC}+\mathrm{TB}$ & 25,14 & 7,57 & 7,26 & 2,98 & 7,68 & 10,12 & \\
\hline Colmo & $\mathrm{AZ}+\mathrm{CC}$ & 18,81 & 15,60 & 11,89 & 2,89 & 7,11 & 10,66 & \multirow{2}{*}{35,73} \\
\hline Coastcross & $\mathrm{AZ}+\mathrm{CC}+\mathrm{TB}$ & 18,86 & 12,27 & 7,81 & 1,13 & 7,68 & 9,55 & \\
\hline \multirow{2}{*}{ Trevo branco } & $\mathrm{AZ}+\mathrm{CC}+\mathrm{TB}$ & 1,37 & $3,52^{\mathrm{a}}$ & $4,57^{\mathrm{a}}$ & $7,11^{\mathrm{a}}$ & $6,03^{\mathrm{a}}$ & $4,52^{\mathrm{a}}$ & \multirow{2}{*}{51,74} \\
\hline & $\mathrm{AZ}+\mathrm{TB}$ & 0,65 & $0,69^{\mathrm{b}}$ & $0,01^{\mathrm{b}}$ & $2,03^{b}$ & $0,88^{\mathrm{b}}$ & $0,85^{\mathrm{b}}$ & \\
\hline \multirow{4}{*}{ Outras espécie } & $\mathrm{AZ}+\mathrm{CC}$ & $0,27^{\mathrm{b}}$ & 1,79 & $0,61^{\mathrm{c}}$ & 3,84 & 1,57 & 1,61 & \multirow{4}{*}{64,59} \\
\hline & $\mathrm{AZ}+\mathrm{CC}+\mathrm{TB}$ & $0,56^{\mathrm{b}}$ & 2,53 & $7,17^{\mathrm{a}}$ & 3,57 & 7,03 & 4,17 & \\
\hline & $\mathrm{AZ}+\mathrm{TB}$ & $5,03^{a}$ & 1,50 & $1,61^{\mathrm{bc}}$ & 2,89 & 1,61 & 2,53 & \\
\hline & $\mathrm{AZ}$ & $3,00^{\mathrm{a}}$ & 0,91 & $4,12^{\mathrm{ab}}$ & 2,17 & 4,12 & 2,86 & \\
\hline
\end{tabular}

‘a b’ médias seguidas por letras distintas, na coluna, diferem entre si $(\mathrm{P}<0,05)$. $\mathrm{T}=$ tratamento.

Os valores de lotação (P>0,05), unidade animal (UA), foram de 3,57; 3,50; 3,097 e 3,03 UA ha ${ }^{-1}$, calculados entre o plantio e o último pastejo, em 161 dias de avaliação.

Ciência Rural, v.39, n.3, mai-jun, 2009. 
adequados, segundo DERESZ et al. (2001), ao se considerarem que tempos de ocupação de 2 a 3 dias e de descanso de 30 dias estão associados à melhor qualidade de forragem e ao maior desempenho animal, se comparados com ciclos de pastejo de 45 dias. Ciclo de pastejo semelhante, com 1 dia de ocupação e 28 dias de descanso, foi observado por FONTANELLI et al. (2005), avaliando pastagens de capim-bermuda, cv. Tifton 85, sobresemeada com centeio e azevém.

Para massa de forragem inicial, houve diferença significativa $(\mathrm{P}<0,05)$ apenas no pastejo efetuado em setembro, havendo similaridade entre os tratamentos constituídos com coastcross. Valores de massa de forragem mais elevados foram observados em todos os tratamentos, nesse período, devido ao azevém que apresenta maior produção entre o final do inverno e o início da primavera, condição essa que pode ser verificada pela participação de lâmina foliar e de colmo dessa forrageira no decorrer dos pastejos (Tabela 1). Comparando-se os tratamentos, observou-se que a presença da coastcross ( $\mathrm{AZ}+\mathrm{CC}$ e $\mathrm{AZ}+\mathrm{CC}+\mathrm{TB}$ ) contribuiu para estender o desenvolvimento do azevém, quando comparado com a pastagem constituída exclusivamente por essa forrageira, além de proporcionar maior uniformidade na disponibilidade de forragem no decorrer dos pastejos. Para os valores médios, não houve diferença entre as pastagens, sendo superiores aos observados por ROCHA et al. (2007), de 1.765,7 e $1.837,7 \mathrm{~kg} \mathrm{ha}^{-1}$ de MS, para aveia e azevém e sobresemeadura dessa mistura em coastcross, usandose manejo similar ao presente trabalho.

Nos tratamentos constituídos por coastcross, houve menor contribuição do azevém. A participação do trevo branco foi maior e mais uniforme no decorrer dos pastejos, no consórcio com azevém e coastcross, provavelmente, devido à menor quantidade de azevém, implicando em menos competitividade. A presença da coastcross contribuiu, possivelmente, para maior cobertura do solo, proporcionando melhores condições para o estabelecimento dessa leguminosa. A participação de outras espécies foi baixa nos diferentes tratamentos. Para o material morto, houve diferença $(\mathrm{P}<0,05)$ somente no primeiro pastejo devido à presença de material senescente da coastcross ( $\mathrm{AZ}+\mathrm{CC}$ e $\mathrm{AZ}+\mathrm{CC}+\mathrm{TB})$, quando comparado com as demais pastagens (azevém + trevo branco e azevém). Para lotação, calculada do plantio ao ultimo pastejo, perfazendo 161 dias, o valor médio foi de 3,30UA ha ${ }^{-1}$, sendo superior aos valores observados por ROCHA et al. (2007), de 2,07 e 2,24UA ha-1, para pastagem constituída por sobresemeadura de aveia e azevém em coastcross e de aveia e azevém, respectivamente.
Com relação ao valor nutritivo (Tabela 2), observa-se que os teores de $\mathrm{MO}$ foram similares entre as pastagens, havendo aumento dos valores nos pastejos efetuados em setembro e outubro. Esse comportamento é confirmado pela análise de regressão, verificando-se que o modelo cúbico foi mais representativo em todos os tratamentos (Tabela 3). Para matéria mineral, observou-se comportamento inverso, com menores teores no final do período hibernal. Possivelmente, esse resultado deve-se às características de dossel das pastagens nesse período, com o alongamento do azevém e a brotação da coastcross, implicando em menor interceptação de luz e menor teor de matéria mineral, conseqüentemente (BUENO et al., 2003).

Com relação à DIVMO, teores mais elevados foram observados no início do período hibernal, condição essa verificada a partir dos modelos de análise de regressão (Tabela 3) que confirmam essa tendência em todos os tratamentos. Entre os pastejos, houve diferença $(P<0,05)$ somente na avaliação efetuada em julho nas pastagens constituídas por azevém + trevo branco ou somente por azevém. Nos demais tratamentos, os valores foram menores devido à presença da coastcross (Tabela 1) que, normalmente, apresenta menor valor nutritivo em relação às gramíneas anuais de ciclo hibernal (STOBBS, 1973). Considerando-se os valores das médias dos pastejos, o melhor teor $(\mathrm{P}<0,05)$ foi obtido no tratamento constituído por azevém e trevo branco.

Comportamento similar à DIVMO foi observado com os valores de NDT, verificando-se teores menores no pastejo efetuado em outubro devido, especialmente, à maior contribuição de colmo de azevém (Tabela 1), que apresenta menor valor nutritivo em relação à folha. Comparando-se os valores das médias dos pastejos, PROHMANN et al. (2004) verificaram teores similares, de 55,8 e 64,7\% de NDT, para bainha mais colmo e lâmina foliar de coastcross, respectivamente.

Para DIVMS, os teores mais elevados foram observados no início do período hibernal (Tabela 2), condição confirmada pelos modelos mais representativos da análise de regressão (Tabela 3), devido à maior contribuição de biomassa de lâmina foliar do azevém nesse período (Tabela 1). Considerando-se os valores médios dos pastejos, os teores mais elevados foram obtidos nas pastagens constituídas por azevém e por azevém e trevo branco. Teores similares de DIVMS foram obtidos por GERDES et al. (2005) com pastagens anuais de inverno.

Além dos valores de DIVMO e DIVMS, também os teores de PB foram mais elevados no 
Tabela 2 - Porcentuais de matéria orgânica (MO), matéria mineral (MM), digestibilidade in vitro da matéria orgânica (DIVMO), nutrientes digestíveis totais (NDT), proteína bruta (PB), fibra em detergente neutro (FDN), digestibilidade in vitro da matéria seca (DIVMS) nas pastagens constituídas por azevém + “coastcross” (AZ+CC), azevém + “coastcross” + trevo branco (AZ+CC+TB), azevém + trevo branco(AZ+ TB) e o azevém (AZ). Santa Maria, RS, 2006.

\begin{tabular}{|c|c|c|c|c|c|c|c|c|}
\hline \multirow[b]{2}{*}{ Parâmetros } & \multirow[b]{2}{*}{ Pastagens } & \multicolumn{5}{|c|}{ 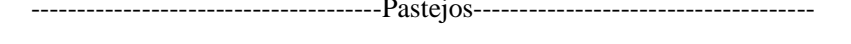 } & \multirow[b]{2}{*}{ Média } & \multirow[b]{2}{*}{$\mathrm{CV}(\%)$} \\
\hline & & $1^{\circ}($ jun/06) & $2^{-}(j u l / 06)$ & $3^{\circ}(\mathrm{ago} / 06)$ & $4^{\circ}($ set/06) & $5^{\circ}($ out $/ 06)$ & & \\
\hline \multirow{4}{*}{ MO } & $\mathrm{AZ}+\mathrm{CC}$ & 87,97 & 87,88 & 88,01 & 89,62 & 92,25 & 89,14 & \multirow{4}{*}{0,88} \\
\hline & $\mathrm{AZ}+\mathrm{CC}+\mathrm{TB}$ & 87,16 & 87,95 & 88,11 & 91,49 & 91,74 & 89,29 & \\
\hline & $\mathrm{AZ}+\mathrm{TB}$ & 88,54 & 89,32 & 88,56 & 90,38 & 93,17 & 89,99 & \\
\hline & AZ & 86,99 & 88,01 & 88,68 & 91,62 & 93,07 & 89,67 & \\
\hline \multirow{4}{*}{ MM } & $\mathrm{AZ}+\mathrm{CC}$ & 12,03 & 12,11 & 11,99 & 10,37 & 7,75 & 10,85 & \multirow{4}{*}{7,60} \\
\hline & $\mathrm{AZ}+\mathrm{CC}+\mathrm{TB}$ & 12,84 & 12,05 & 11,89 & 8,50 & 9,26 & 10,70 & \\
\hline & $\mathrm{AZ}+\mathrm{TB}$ & 11,46 & 10,68 & 11,44 & 9,61 & 6,83 & 10,32 & \\
\hline & $\mathrm{AZ}$ & 13,01 & 11,99 & 11,32 & 8,38 & 6,93 & 10,03 & \\
\hline \multirow{4}{*}{ DIVMO } & $\mathrm{AZ}+\mathrm{CC}$ & 73,04 & $68,43^{\mathrm{b}}$ & 74,19 & 65,66 & 56,27 & $67,52^{\mathrm{b}}$ & \multirow{4}{*}{4,06} \\
\hline & $\mathrm{AZ}+\mathrm{CC}+\mathrm{TB}$ & 71,06 & $72,16^{\mathrm{ab}}$ & 72,85 & 67,36 & 57,46 & $68,18^{\mathrm{b}}$ & \\
\hline & $\mathrm{AZ}+\mathrm{TB}$ & 76,87 & $76,12^{\mathrm{a}}$ & 76,28 & 70,80 & 62,48 & $72,51^{\mathrm{a}}$ & \\
\hline & $\mathrm{AZ}$ & 75,29 & $76,35^{\mathrm{a}}$ & 74,12 & 68,18 & 54,94 & $69,78^{\mathrm{ab}}$ & \\
\hline \multirow{4}{*}{ NDT } & $\mathrm{AZ}+\mathrm{CC}$ & 61,82 & $59,32^{\mathrm{b}}$ & 62,42 & 59,03 & 55,60 & $59,64^{\mathrm{b}}$ & \multirow{4}{*}{2,63} \\
\hline & $\mathrm{AZ}+\mathrm{CC}+\mathrm{TB}$ & 60,21 & $61,33^{\mathrm{ab}}$ & 61,82 & 61,20 & 55,94 & $60,10^{\mathrm{b}}$ & \\
\hline & $\mathrm{AZ}+\mathrm{TB}$ & 64,22 & $63,57^{\mathrm{a}}$ & 63,93 & 62,30 & 59,60 & $62,89^{a}$ & \\
\hline & $\mathrm{AZ}$ & 62,29 & $64,39^{\mathrm{a}}$ & 62,88 & 61,72 & 55,36 & $61,16^{\mathrm{ab}}$ & \\
\hline \multirow{4}{*}{ PB } & $\mathrm{AZ}+\mathrm{CC}$ & $23,18^{\mathrm{ab}}$ & 22,63 & $28,47^{\mathrm{a}}$ & 16,97 & 15,04 & $21,73^{b}$ & \multirow{4}{*}{8,06} \\
\hline & $\mathrm{AZ}+\mathrm{CC}+\mathrm{TB}$ & $22,62^{\mathrm{b}}$ & 23,12 & $28,64^{\mathrm{ab}}$ & 17,60 & 16,10 & $21,49^{b}$ & \\
\hline & $\mathrm{AZ}+\mathrm{TB}$ & $27,02^{\mathrm{b}}$ & 29,69 & $31,43^{a}$ & 23,90 & 14,47 & $25,11^{\mathrm{a}}$ & \\
\hline & $\mathrm{AZ}$ & $29,17^{\mathrm{a}}$ & 28,03 & $30,15^{\mathrm{ab}}$ & 19,11 & 12,59 & $23,81^{\mathrm{ab}}$ & \\
\hline \multirow{4}{*}{ FDN } & $\mathrm{AZ}+\mathrm{CC}$ & $58,20^{\mathrm{a}}$ & $44,62^{\mathrm{a}}$ & 43,22 & 60,42 & 71,60 & $55,11^{\mathrm{a}}$ & \multirow{4}{*}{5,15} \\
\hline & $\mathrm{AZ}+\mathrm{CC}+\mathrm{TB}$ & $55,04^{\mathrm{a}}$ & $43,39^{a}$ & 41,79 & 57,93 & 68,36 & $53,97^{a}$ & \\
\hline & $\mathrm{AZ}+\mathrm{TB}$ & $39,01^{b}$ & $36,06^{\mathrm{b}}$ & 43,77 & 53,92 & 69,22 & $48,22^{b}$ & \\
\hline & $\mathrm{AZ}$ & $41,10^{\mathrm{b}}$ & $37,10^{\mathrm{b}}$ & 44,52 & 57,31 & 70,93 & $50,20^{\mathrm{b}}$ & \\
\hline \multirow{4}{*}{ DIVMS } & $\mathrm{AZ}+\mathrm{CC}$ & 74,32 & $69,28^{\mathrm{b}}$ & 75,58 & 67,41 & 58,50 & $69,02^{\mathrm{b}}$ & \multirow{4}{*}{3,61} \\
\hline & $\mathrm{AZ}+\mathrm{CC}+\mathrm{TB}$ & 72,87 & $72,01^{\mathrm{ab}}$ & 75,26 & 68,76 & 59,42 & $69,66^{\mathrm{b}}$ & \\
\hline & $\mathrm{AZ}+\mathrm{TB}$ & 78,04 & $77,02^{\mathrm{a}}$ & 77,90 & 72,33 & 63,64 & $73,78^{a}$ & \\
\hline & $\mathrm{AZ}$ & 76,41 & $76,97^{\mathrm{a}}$ & 76,63 & 69,95 & 57,02 & $71,40^{\mathrm{ab}}$ & \\
\hline
\end{tabular}

‘a b’ médias seguidas por letras distintas, na coluna, diferem entre si $(\mathrm{P}<0,05)$. $\mathrm{T}=$ tratamento.

Amostras obtidas mediante simulação de pastejo.

inverno, em todas as pastagens (Tabela 2) devido à maior contribuição de biomassa de lâminas foliares do azevém. Os modelos de análise de regressão demonstram essa tendência (Tabela 3). Esse comportamento pode ser justificado pelo maior desenvolvimento do azevém no final do inverno e início da primavera, havendo elevação nos teores de MS, parede celular, celulose, fibra e lignina com diminuição de valor nutritivo. Esse comportamento pode ser constatado, em parte, pelas correlações, verificadas entre PB e FDN, em todos os tratamentos, sendo mais representativa, $(r=-0,95 ; P=0,001)$, no entanto, na pastagem constituída somente por azevém. Valores de $\mathrm{PB}$, semelhantes aos encontrados no presente trabalho, foram observados por ROCHA et al. (2007).

Para FDN, as diferenças observadas, $(\mathrm{P}<0,05)$ nos dois pastejos iniciais, devem-se à participação da coastcross na composição das pastagens, devido ao aumento de material senescente dessa forrageira nesse período (Tabela 1). A elevação 
Tabela 3 - Modelos de análise de regressão dos parâmetros de valor nutritivo no decorrer dos pastejos nas pastagens constituídas por azevém + coastcross (AZ+CC), azevém + coastcross + trevo branco (AZ+CC+TB), azevém + trevo branco(AZ+ TB) e o azevém (AZ). Santa Maria, RS, 2006.

\begin{tabular}{|c|c|c|c|}
\hline Parâmetros & Pastagens & Modelo & $r^{2}$ \\
\hline \multirow{4}{*}{ MO } & $\mathrm{AZ}+\mathrm{CC}$ & $88,12-0,033 x+0,00066 x^{2}$ & 0,90 \\
\hline & $\mathrm{AZ}+\mathrm{CC}+\mathrm{TB}$ & $86.80+0,048 x$ & 0,80 \\
\hline & $\mathrm{AZ}+\mathrm{TB}$ & $88,94-0,03 x+0,00065 x^{2}$ & 0,87 \\
\hline & $\mathrm{AZ}$ & $86,72+0,05 x$ & 0,94 \\
\hline \multirow{4}{*}{ MM } & $\mathrm{AZ}+\mathrm{CC}$ & $11,87+0,003 x-0,00066 x^{2}$ & 0,90 \\
\hline & $\mathrm{AZ}+\mathrm{CC}+\mathrm{TB}$ & $13,19-0,048 x$ & 0,80 \\
\hline & $\mathrm{AZ}+\mathrm{TB}$ & $11,05+0,03 x-0,00065 x^{2}$ & 0,87 \\
\hline & $\mathrm{AZ}$ & $13,37-0,05 x$ & 0,94 \\
\hline \multirow{4}{*}{ DIVMO } & $\mathrm{AZ}+\mathrm{CC}$ & $71,09+0,124 x-0,0029 x^{2}$ & 0,72 \\
\hline & $\mathrm{AZ}+\mathrm{CC}+\mathrm{TB}$ & $70,35+0,18 x-0,00028 x^{2}$ & 0,84 \\
\hline & $\mathrm{AZ}+\mathrm{TB}$ & $79,17-0,12 x$ & 0,80 \\
\hline & $\mathrm{AZ}$ & $74,72+0,15 x-0,003 x^{2}$ & 0,95 \\
\hline \multirow{3}{*}{ NDT } & $\mathrm{AZ}+\mathrm{CC}+\mathrm{TB}$ & $59,71+0,12 x-0,0014 x^{2}$ & 0,63 \\
\hline & $\mathrm{AZ}+\mathrm{TB}$ & $64,13+0,028 x-0,00065 x^{2}$ & 0,95 \\
\hline & $\mathrm{AZ}$ & $61,92+0,11 x-0,0015 x^{2}$ & 0,87 \\
\hline \multirow{4}{*}{ PB } & $\mathrm{AZ}+\mathrm{CC}$ & $22,31+0,17 x-0,0023 x^{2}$ & 0,77 \\
\hline & $\mathrm{AZ}+\mathrm{CC}+\mathrm{TB}$ & $22,50+0,14 x-0,002 x^{2}$ & 0,64 \\
\hline & $\mathrm{AZ}+\mathrm{TB}$ & $26,23+0,24 x-0,003 x^{2}$ & 0,96 \\
\hline & $\mathrm{AZ}$ & $28,74+0,089 x-0,0022 x^{2}$ & 0,89 \\
\hline \multirow{4}{*}{ FDN } & $\mathrm{AZ}+\mathrm{CC}$ & $57,30-0,61 x+0,007 x^{2}$ & 0,93 \\
\hline & $\mathrm{AZ}+\mathrm{CC}+\mathrm{TB}$ & $53,57-0,48 x+0,006 x^{2}$ & 0,85 \\
\hline & $\mathrm{AZ}+\mathrm{TB}$ & $33,33-0,28 x$ & 0,88 \\
\hline & $\mathrm{AZ}$ & $34,60-0,30 x$ & 0,86 \\
\hline \multirow{4}{*}{ DIVMS } & $\mathrm{AZ}+\mathrm{CC}$ & $72,26+0,12 x-0,0026 x^{2}$ & 0,74 \\
\hline & $\mathrm{AZ}+\mathrm{CC}+\mathrm{TB}$ & $71,64+0,17 x-0,0027 x^{2}$ & 0,80 \\
\hline & $\mathrm{AZ}+\mathrm{TB}$ & $77,19+0,10 x-0,0021 x^{2}$ & 0,94 \\
\hline & $\mathrm{AZ}$ & $75,56+0,18 x-0,0032 x^{2}$ & 0,94 \\
\hline
\end{tabular}

$(\mathrm{P}<0,05) ; \mathrm{MO}=$ matéria orgânica; $\mathrm{MM}=$ matéria mineral; DIVMO = digestibilidade in vitro da MO; NDT = nutrientes digestíveis totais; PB = proteína bruta; FDN = fibra em detergente neutro; DIVMS = digestibilidade in vitro da matéria seca.

dos teores de FDN nos pastejos efetuados em setembro e outubro (Tabela 3) deve-se ao azevém com aumento da sua biomassa constituída especialmente por colmos, estrutura essa que se apresenta mais fibrosa em relação às lâminas foliares. Valores médios menores de FDN, de 41,7 e de $43,7 \%$, foram observados por ROCHA et al. (2007), em pastagem constituída por aveia e azevém sob dois métodos de estabelecimento. GERDES et al. (2005) verificaram teor maior, de 69,5\%, em pastagem de capim-aruana (Panicum maximum Jacq. cv. 'Aruana'), sobresemeada com aveia e azevém. $\mathrm{Na}$ pastagem de azevém (T4), verificaram-se associações inversas da FDN com a DIVMS ( $\mathrm{r}=$ -0,96; $\mathrm{P}=0,0079)$, a DIVMO ( $\mathrm{r}=-0,97 ; \mathrm{P}=0,0044)$ e o NDT $(\mathrm{r}=-0,91 ; \mathrm{P}=0,029)$. Nas pastagens constituídas por coastcross, essas associações foram menos representativas, demonstrando que a presença dessa forrageira proporcionou maior equilíbrio no valor nutritivo das pastagens em relação àquela estabelecida singularmente com azevém.

Resultados antagônicos ao presente trabalho, com menor teor de FDN, em pastagem de coastcross sobresemeada com aveia e azevém em relação ao cultivo estreme dessas gramíneas anuais foram obtidos por ROCHA et al. (2007). Resultados similares, com declínio do valor nutritivo no decorrer da utilização, foram observados por FONTANELI et al. (2005), em pastagem de Tifton 85, sobresemeada com centeio e azevém, verificando teores de DIVMO de 78,7 e 70,3\%; PB de 26,8 e 22,1\% e de FDN de 44,1 e $51,5 \%$ no início e no final do período hibernal.

Considerando-se o mesmo período (hibernal) e forma de amostragem (pastejo simulado), os valores obtidos de PB, FDN e DIVMS foram, em média, superiores aos obtidos por CARNEVALLI et al. (2001) em pastagem singular de coastcross, fertilizada com $280 \mathrm{~kg}$ de $\mathrm{N}$ ha $^{-1}$, que também apresentaram menor variabilidade no decorrer da utilização.

\section{CONCLUSÕES}

Em todas as pastagens avaliadas, melhores resultados de valor nutritivo foram observados nos primeiros pastejos, devido à maior contribuição de biomassa de lâminas foliares do azevém. A presença de coastcross nas misturas constituídas diminuiu levemente o valor nutritivo, embora contribua para equilibrar a oferta de forragem, especialmente no início e final do período hibernal, quando comparado às pastagens de azevém e trevo branco ou somente azevém. Associando-se à produção de forragem, ao valor nutritivo dos pastos e à carga animal, além da possibilidade de uso da área estabelecida com pastagem perene de ciclo estival ser usada em todo o período hibernal, os resultados apontam os tratamentos constituídos com coastcross como mais promissores. 


\section{REFERÊNCIAS}

ASSOCIATION OF OFFICIAL ANALYTICAL CHEMISTS A.O.A.C. Official methods of analysis. 14.ed. Washington, D.C. $1995.1094 p$.

BUENO, A.A.O. Características estruturais do dossel forrageiro, valor nutritivo e produção de forragem em pastos de capim-mombaça submetidos a regimes de lotação intermitente. 2003. 76fp. Dissertação (Mestrado em Agronomia) - Escola Superior de Agricultura Luiz de Queiroz, Universidade de São Paulo.

CARNEVALLI, R.A. et al. Desempenho de ovinos e respostas de pastagens de coastcross submetidas a regimes de desfolha sob lotação contínua. Pesquisa Agropecuária Brasileira, v.36, n.6, p.919-927, 2001.

COMISSÃO DE QUÍMICA E FERTILIDADE DO SOLO - RS/ SC. Manual de adubação e calagem para os estados do Rio Grande Do Sul e Santa Catarina. Porto Alegre: SBCSNRS, 2004. 400p.

DERESZ, F. et al. Produção de leite de vacas mestiças holandês $x$ zebu em pastagem de capim-elefante, com e sem suplementação durante a época das chuvas. Arquivo Brasileiro de Medicina Veterinária e Zootecnia, v.55, n.3, p.334-340, 2001.

EMBRAPA. Centro Nacional de Pesquisa Agropecuária. Sistema brasileiro de classificação de solos. Brasília: EMBRAPA, 1999. 412p.

EUCLIDES, V.P.B. et al. Avaliação de diferentes métodos de amostragens sob pastejo. Revista Brasileira de Zootecnia, v.21, n.4, p.691-702, 1992.

FONTANELI, R.S. et al. Performance of lactating dairy cows managed on pasture-based or in freestall barn-feeding systems. Journal of Dairy Science, v.88, n.3, p.1264-1276, 2005.

GERDES, L. et al. Composição química e digestibilidade da massa de forragem em pastagem irrigada de capim-aruana exclusivo ou sobre-semeado com mistura de aveia preta e azevém. Revista Brasileira de Zootecnia, v.34, n.4, p.10981108, 2005.
KUNKLE, W.E.; BATES, D.B. Evaluating feed purchasing options: energy, protein, and mineral supplements. In: FLORIDA BEEF CATTLE SHORT COURSE, 1998, Gainesville. Proceedings... Gainesville: University of Florida, 1998. p.5970 .

MORENO, J.A. Clima do Rio Grande do Sul. Porto Alegre: Secretaria da Agricultura, 1961. 41p.

PROHMANN, P.E.F. et al. Suplementação de bovinos em pastagens de Coastcross (Cynodon dactylon L. Pers) no inverno. Revista Brasileira de Zootecnia, v.33, n.4, p.801810, 2004

ROCHA, M.G. et al. Produção e qualidade de forragem da mistura de aveia e azevém sob dois métodos de estabelecimento. Revista Brasileira de Zootecnia, v.36, n.1, p.7-15, 2007.

SAS INSTITUTE, SAS, User's guide: statistics. Version 6.11. Cary, North Carolin, 1997. 1187p.

STOBBS, T.H. The effect of plant structure on the intake of tropical pasture. 2. Differences in sward structure, nutritive value, and bite size of animals grazing Setaria anceps and Chloris gayana at various stages of growth. Australian Journal of Agricultural Research, v.24, n.6, p.821-829, 1973

TILLEY, J.M.A.; TERRY, R.A. A two-stage technique of the "in vitro" digestion of forage crop. Journal of the British Grassland Society, v.18, n.2, p.104-111, 1963.

VAN SOEST, P.J. et al. Methods for dietary fiber, neutral detergent fiber, and nonstarch polysaccharides in relation to animal nutrition. Journal of Dairy Science, v.74, n.1, p.35833597, 1991.

VILELA, D. et al. Desempenho de vacas da raça holandesa em pastagem de coastcross. Revista Brasileira de Zootecnia, v.35, n.2, p.555-561, 2006

WILM, H.G. et al. Estimating forage yield by the double sampling method. Journal of the American Society for Agriculture, v.36, n.1, p.194-203, 1944. 